J. Clin. Chem. Clin. Biochem.

Vol. 19, 1981, pp. 209-212

\title{
Reference Values and Analytical Performance of the Hydroxyproline/Creatinine Ratio in Early Morning Urine Samples
}

\author{
By F. D. Posma, H. Groenewold, O. Kluft and F. H. B. Tuynman \\ Departments of Clinical Laboratory, Urology, Surgery and Radiology, Princess Irene Hospital, Almelo, The Netherlands
}

(Received April 21/November 23, 1980)

Summary: The hydroxyproline/creatinine ratio for two groups of healthy individuals and two groups of patients with a history of mammary and prostatic carcinoma without metastases was measured and compared with literature values.

The hydroxyproline/creatinine ratio for healthy adults appears to be 1.4 (range $0.7-2.3$ ). Furthermore, the influence of diet and gelatin load of $30 \mathrm{~g}$ on the hydroxyproline creatinine ratio and the hydroxyproline excretion has been investigated. The analytical characteristics of the test used in the present study were evaluated using the method of standard additions. An intra-assay quality-control on the basis of the standard addition is proposed. The coefficient of variation of the hydroxypyroline/creatinine ratio appears to be $22 \%$. The intraindividual variability has also been established for the hydroxyproline/creatinine ratio and appears to be $25 \%$.

\section{Referenzwerte und analytische Ermittlung des Hydroxyprolin/Kreatinin-Quotienten in Proben von Morgenurin}

Zusammenfassung: Der Hydroxyprolin/Kreatinin-Quotient wurde bei zwei Gruppen Gesunder und zwei Gruppen mit der Anamnese von Mamma- bzw. Prostata-Carcinom ohne Metastasen bestimmt und mit Werten der Literatur verglichen. Der Hydroxyprolin/Kreatinin-Quotient für gesunde Erwachsene ergab sich zu 1,4 (Bereich 0,7-2,3). Weiterhin wurde der Einfluß der Nahrung und einer Belastung mit $30 \mathrm{~g}$ Gelatine auf den Hydroxyprolin/KreatininQuotienten und die Hydroxyprolinausscheidung untersucht. Die analytischen Charakteristika für den hier verwendeten Test wurden mit der Methode der Standardaddition geprüft. Auf der Grundlage der Standardaddition wird eine Qualitätskontrolle in jeder Probe vorgeschlagen. Der Variationskoeffizient für den Hydroxyprolin/KreatininQuotienten ergab sich zu 22\%, die intraindividuelle Variabilität zu $25 \%$.

\section{Introduction}

Hydroxyproline excretion in urine has been reported to be useful for monitoring patients with mammary carcinoma or prostatic carcinoma, for the detection of bone metastases (1-7).

Also, it is particularly useful in the clinical follow up, for the evaluation of the response to treatment.

However, until recently hydroxyproline excretion was measured in accurately collected 24 hour urine samples. Since the hydroxyproline excretion may be influenced by dietary collagen, a collagen-free diet before and during the urine collection is considered necessary.

It will be clear that the collection of the 24-hour urine during a collagen free diet is rather troublesome for routine use in an outpatients clinic. A simplification of the procedure has been proposed by Powles et al. (8) using an early morning urine sample collected after a 10hour overnight fast. Recently a comparison was made between early morning urine hydroxyproline levels and hydroxyproline excretion $(9,10)$. The present investigation is part of a clinical study of patients with mammary carcinoma and prostatic carcinoma during a two-year follow up with emphasis on the detection of bone metastasis. Since reported reference values for the hydroxyproline/creatinine ratio in early morning urine $(3-6,8,9)$ showed large differences, the authors found it necessary to evaluate the hydroxyproline creatine/ ratio for normal healthy individuals and for patients without metastases. Furthermore, since the coefficient of variation of the hydroxyproline/creatinine ratio was relatively large it appeared indispensable for the interpretation of the results to investigate the intraindividual variability of the hydroxyproline/creatinine ratio. 


\section{Materials and Methods}

\section{Volunteers}

25 normal healthy laboratory workers ( 18 females, 7 males, age 21-42 years) participated in the investigation.

They followed the following protocol for 5 days:

$1^{\text {st }}$ day: starting at 8.00 hours with collagen-free diet.

$2^{\text {nd }}$ day: collagen-free diet continued; 24 hour urine collection started after the first morning quantity had been voided.

$3^{\text {rd }}$ day: first morning urine collected and kept separate from the 24-hour urine. A small portion of this first morning urine was used for analyses and the remaining portion was added to the 24-hour urine. Diet then discontinued. At 22.00 hours overnight fast started (no food or drinks).

$4^{\text {th }}$ day: first quantity of urine discarded. Fasting then continued and a urine sample collected after about 30-60 min. At about 15.00 hours $30 \mathrm{~g}$ gelatin dissolved in fruit juice was taken per os. At 22.00 hours overnight fast started.

$5^{\text {th }}$ day: first morning urine discarded. Urine sample then collected after about $30-60 \mathrm{~min}$.

Another 58 healthy adults (44 females and 14 males, age 21-63 years) cooperated to collect a spot early morning urine after an overnight fast (no food, no drinks) starting at 22.00 hours. The first moming urine had to be discarded and a following urine sample was collected after about $30-60 \mathrm{~min}$.

\section{Patients}

26 patients with biopsy-proven mammary carcinoma without any metastases (age: mean 62 years, range 39-83 years); and 24 patients with biopsy-proven prostatic carcinoma without any metastases (age: mean 74 years, range 60-90 years), collected, every 3 to 4 months, a spot fasting morning urine during their visit to the laboratory.

Before this investigation all patients with mammary carcinoma and prostatic carcinoma were operated and underwent a thorough clinical evaluation for full staging and assessment on the basis of careful examination by a surgeon or an urologist.

Extensive laboratory and radiological investigations were performed including: bone scan (Tc polyphosphate); chest X-ray and skeletal survey; routine haematology; renal function; liver function; C.E.A.; $\alpha$-fetoprotein; ferritin; biopsy for histological examinations.

During this investigation the patients had normal renal function, and there were no indications of other metabolic diseases.

\section{Procedure}

Hydroxyproline in urine was measured by means of the hypronosticon test kit (Organon n.v., Oss, The Netherlands). The test involves hydrolysis of peptide bound hydroxyproline.
The hydroxyproline is oxidized to pyrrole compounds that form a specific colour reaction with $p$-dimethylaminobenzaldehyde. The absorbance of the coloured compound is measured at $520 \mathrm{~nm}$. A detailed description of test principles and reagents has been outlined by Goverde \& Veenkamp (11) and by others (12).

The urines were analyzed in duplicate: two urine tubes U1 and U2; two urine + standard tubes S1 and S2; and two blank tubes B1 and B2. Standardization was performed by means of standard addition to each sample. The amount added was $382 \mu \mathrm{mol}$.

Creatinine measurements were performed by means of a standard Technicon Autoanalyzer method.

Urine samples: all urines were frozen and kept at $-20^{\circ} \mathrm{C}$ prior to determination.

\section{Results and Discussion}

Since each hydroxyproline measurement is standardized by means of standard addition, this means that quality control can be performed on each individual sample.

The possibility of individual sample quality control follows from measurement of the increase in absorbance caused by the addition of standard. On the basis of linearity of the working curve this increase in absorbance should be constant, depending only on the variability of the absorbance readings.

The variability of the absorbance readings was studied within a series and during 15 series.

On the basis of these results it was obvious that the coefficient of variation of the hydroxyproline creatinine ratio appeared to be $22 \%$.

Furthermore, it was clear that every result with an increase in absorbance outside the range 0.400-0.585 had to be omitted. The urines of the 25 volunteers who undertook the five-day protocol were analysed. The results of the hydroxyproline excretion and hydroxyproline/creatinine ratios are summarized in table 1. Furthermore, the results of another collection of fasting morning urines of 58 volunteers (different from the first group), who recently served as reference group for our laboratory, have been included in table 1 .

Tab. 1. Hydroxyproline excretion and hydroxyproline/creatinine ratios for volunteers under various conditions.

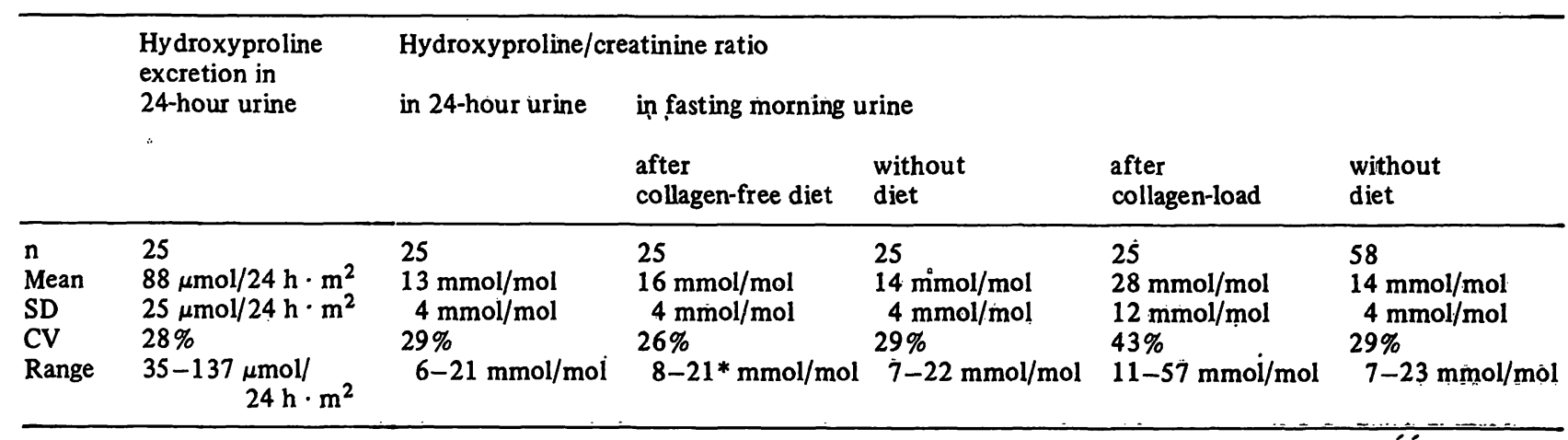

* An outlier of $29 \mathrm{mmol} / \mathrm{mol}$ has been deleted. 
Evidently, the hydroxyproline creatinine ratio is not influenced by normal dietary intake of collagen, since there are no significant differences between early morning urine with and without diet. Also the hydroxyproline/creatinine ratio of the reference group is not significantly different from the values for the first group of volunteers. Between both measurements there was a time lag of one year, indicating that the method appears to be reproducible over long periods using different batch numbers of reagents.

The normal values for the hydroxyproline excretion as shown in table 1, are slightly lower than the reference values as stated by the kit supplier.

As is clearly demonstrated from the figures of table 1 , the hydroxyproline/creatinine ratios increase significantly after a dietary load of $30 \mathrm{~g}$ gelatin. Since normal dietary hydroxyproline intake is relatively low it will be clear that the risk of false high values due to excessive dietary intake is low compared to other risks of false positive results e.g. intra individual variations. Also from table 1 it will be obvious that the influence of dietary intake on fasting hydroxyproline excretion is not measurable.

Comparison of reference values with the hydroxyproline/creatinine ratios from the literature was confusing: Firstly, because the literature values are often expressed as $\mathrm{g} / \mathrm{g}$ ratio. Secondly, a great number of literature results were deduced from patient groups with benign tumours or patients (mammary carcinoma, prostatic carcinoma) without metastases.

The reference values found in the literature are given in table 2 . These values show a rather large variability, possibly caused by method differences, and material differences. The upper limits of the normal values range from 2.3 to 4.3 .

To study the possible differences between healthy individuals and patients without bone metastases, we have included in this study a 1 year follow up of 26 patients with a history of mammary carcinoma and 24 patients with a history of prostatic carcinoma.

Furthermore it was important for the interpretation of hydroxyproline/creatinine ratios to know the intra-
Tab. 3. Intra-individual variations in hydroxyproline/creatinine ratio in early morning urine of 24 patients with prostatic carcinoma without proven metastases. The patients visited the outpatient clinic every 3 to 4 months, during a follow up study after treatment, at least 3 times.

\begin{tabular}{|c|c|c|c|c|}
\hline Patient & No. of visits & $\begin{array}{l}\text { Hydroxy prol } \\
\text { creatinine rat } \\
\text { mean } \\
(\mathrm{mmol} / \mathrm{mol})\end{array}$ & $\begin{array}{l}\text { ine/ } \\
\text { io } \\
\text { SD } \\
\text { (mmol } / \mathrm{mol})\end{array}$ & $\begin{array}{l}\text { CV } \\
(\%)\end{array}$ \\
\hline $\begin{array}{l}1 \\
2 \\
3 \\
4 \\
5 \\
6 \\
7 \\
8 \\
9 \\
10 \\
11 \\
12 \\
13 \\
14 \\
15 \\
16 \\
17 \\
18 \\
19 \\
20 \\
21 \\
22 \\
23 \\
24 \\
\text { Mean }\end{array}$ & $\begin{array}{l}3 \\
3 \\
3 \\
3 \\
4 \\
5 \\
3 \\
5 \\
3 \\
3 \\
3 \\
4 \\
3 \\
3 \\
3 \\
4 \\
3 \\
3 \\
4 \\
3 \\
3 \\
3 \\
3 \\
3\end{array}$ & $\begin{array}{r}21 \\
18 \\
14 \\
14 \\
8 \\
18 \\
10 \\
7 \\
12 \\
13 \\
17 \\
16 \\
7 \\
8 \\
15 \\
6 \\
10 \\
12 \\
7 \\
21 \\
9 \\
7 \\
15 \\
8 \\
12\end{array}$ & $\begin{array}{l}1 \\
7 \\
5 \\
1 \\
3 \\
6 \\
2 \\
1 \\
7 \\
4 \\
3 \\
2 \\
1 \\
3 \\
5 \\
1 \\
4 \\
9 \\
1 \\
6 \\
3 \\
2 \\
3 \\
2 \\
4\end{array}$ & $\begin{array}{r}3 \\
41 \\
36 \\
4 \\
32 \\
35 \\
17 \\
16 \\
63 \\
31 \\
19 \\
15 \\
9 \\
39 \\
32 \\
8 \\
36 \\
75 \\
13 \\
27 \\
29 \\
25 \\
16 \\
27 \\
27\end{array}$ \\
\hline
\end{tabular}

individual variability of results. The follow up results of these groups of patients without metastases and with normal renal function are presented in table 3 and 4 . The mean hydroxyproline creatinine ratios of 1.2 and 1.3 are not significantly different from the reference values discussed above. This means that our group of patients gave the same results as the "normal" groups, indicating that the above mentioned differences in literature values have to be attributed to method differences alone. The mean coefficients of variation of the patient results during a year follow up, appeared to be $27 \%$ and $24 \%$ for the group of mammary carcinoma patients and prostatic carcinoma patients, respectively. Since the

Tab. 2. Comparison of reference values found in this study with literature values for hydroxyproline/creatinine ratio (mmol/mol).

\begin{tabular}{|c|c|c|c|c|c|c|c|}
\hline Ref. & $\begin{array}{l}\text { This study } \\
(-)\end{array}$ & $\begin{array}{l}\text { Guzzo et. al. } \\
\text { (4) }\end{array}$ & $\begin{array}{l}\text { Gielen et al. } \\
\text { (6) }\end{array}$ & $\begin{array}{l}\text { Roberts et al } \\
\text { (5) }\end{array}$ & $\begin{array}{l}\text { Powles et al. } \\
\text { (8) }\end{array}$ & $\begin{array}{l}\text { Cushieri et al. } \\
\text { (3) }\end{array}$ & $\begin{array}{l}\text { Gasser et al. } \\
\text { (9) }\end{array}$ \\
\hline $\begin{array}{l}\text { Mean } \\
\text { Range } \\
\text { n }\end{array}$ & $\begin{array}{l}14 \\
7-23 \\
58\end{array}$ & $\begin{array}{l}19 \\
9-29 \\
16\end{array}$ & $\begin{array}{l}28 \\
12-43 \\
60\end{array}$ & $\begin{array}{l}15 \\
4-25 \\
19\end{array}$ & $\begin{array}{l}19 \\
3-34 \\
12\end{array}$ & $\begin{array}{l}15 \\
6-24 \\
18\end{array}$ & $\begin{array}{l}18 \\
6-30 \\
37\end{array}$ \\
\hline
\end{tabular}


Tab. 4. Intra-individual variations in hydroxyproline/creatinine ratio in early morning urine of 26 patients with mammary carcinoma, without proven metastases. The patients visited the outpatients clinic every 3 to 4 months, during a follow up after treatment, at least 4 times.

\begin{tabular}{|c|c|c|c|c|}
\hline \multirow[t]{2}{*}{ Patient } & \multirow[t]{2}{*}{ No. of visits } & \multicolumn{3}{|c|}{$\begin{array}{l}\text { Hydroxyproline/ } \\
\text { creatinine ratio }\end{array}$} \\
\hline & & $\begin{array}{l}\text { mean } \\
(\mathrm{mmol} / \mathrm{mol})\end{array}$ & $\begin{array}{l}\mathrm{SD} \\
(\mathrm{mmol} / \mathrm{mol})\end{array}$ & $\begin{array}{l}\text { CV } \\
(\%)\end{array}$ \\
\hline 1 & 5 & 16 & 5 & 33 \\
\hline 2 & 4 & 11 & 3 & 29 \\
\hline 3 & 4 & 13 & 5 & 41 \\
\hline 4 & 4 & 10 & 3 & 27 \\
\hline 5 & 4 & 14 & 4 & 28 \\
\hline 6 & 4 & 16 & 3 & 21 \\
\hline 7 & 4 & 11 & 1 & 9 \\
\hline 8 & 5 & 14 & 2 & - 15 \\
\hline 9 & 4 & 11 & 3 & 25 \\
\hline 10 & 5 & 14 & 4 & 30 \\
\hline 11 & 4 & 13 & 2 & 13 \\
\hline 12 & 4 & 17 & 3 & 19 \\
\hline 13 & 4 & 11 & 1 & 5 \\
\hline 14 & 5 & 19 & 3 & 17 \\
\hline 15 & 5 & 12 & 3 & 23 \\
\hline 16 & 4 & 14 & 3 & 24 \\
\hline 17 & 4 & 16 & 6 & 39 \\
\hline 18 & 4 & 10 & 4 & 39 \\
\hline 19 & 4 & 10 & 3 & 36 \\
\hline 20 & 6 & 14 & 3 & 22 \\
\hline 21 & 5 & 9 & 1 & 15 \\
\hline 22 & 5 & 12 & 2 & 17 \\
\hline 23 & 4 & 11 & 2 & 17 \\
\hline 24 & 4 & 15 & 3 & 21 \\
\hline 25 & 4 & 12 & 2 & 17 \\
\hline 26 & 5 & 14 & 5 & 35 \\
\hline Mean & & 13 & 3 & 24 \\
\hline
\end{tabular}

\section{References}

1. Konturi, M. J., Sotaniemie, E. A. \& Larmi, T. K. I. (1974), Scand. J. Urol. Nephrol 8, 91-95.

2. Burkhardt, H., Wepler, R., Burkhardt, F. \& Rommel, K. (1975), Med. Welt, 26, 1411-1415.

3. Cuschieri, A. (1973), Br. J. Surg., 60, 800-803.

4. Guzzo, C. E., Pachas, W. N., Pinals, R. S. \& Krant, M. J. (1969), Cancer, 24, 382-387.

5. Roberts, J. G., Williams, M., Henk, J. M., Blight, A. S. \& Baum, M. (1975), Clin. Oncology, 1, 33-43.

6. Gielen, F., Dequeker, J., Drochmans, A. \& Merlevede, M. (1976), Br. J. Cancer, 34, 279-285. method error is $22 \%$, this implies that the individual results are significantly influenced by the analytical variability of the method.

However, due to these relatively large variations, we feel that the hydroxyproline/creatinine ratio can be used in follow up studies, but every borderline result should be repeated. In conclusion it can be said that the reference values for a group of normal adults is not significantly different from a group of patients with a history of mammary carcinoma or prostatic carcinoma and without proven metastases.

Furthermore, it is very important, at least with the used technique, to perform standard addition on every sample for quality control.

Since the intraindividual variability can be considerable, it is advisable to use a series of results per patient in the interpretation.

\section{Acknowledgement}

We are indebted to Drs. J. J. F. Hasselman for his support in this investigation and for the many helpful discussions.

7. Bischop, M. C. \& Fellows, G. J. (1977), Br. J. Urol. 49, 711-716.

8. Powles, T. J., Rosset, G., Lease, C. L. \& Bondy, P. K. (1976), Cancer, 38, 2564-2566.

9. Gasser, A. B., Depierre, D. \& Courvoisier, B. (1979), Br. J. Cancer, 39, 280-283.

10. Mundy, A. R. (1979), Br. J. Urol., 51, 570-574

11. Goverde, B. C. \& Veenkamp, F. J. N. (1972), Clin. Chim. Acta, 41, 29-40.

12. Burkhardt, H., Burkhardt, F., Wepler, R. \& Rommel, K. (1974). Z. Klin. Chem. Klin. Biochem., 12, 108-115.
Dr. F. D. Posma

Clinical Laboratory Princess Irene Hospital Almelo, The Netherlands 